\title{
Strategy for the Management and Prognosis of Ovarian Cancer in Sub-Saharan Africa: Experience from the National Hospital Center of Pikine, Dakar-Senegal
}

\author{
Moussa Diallo*, Abdoul Aziz Diouf, Mamour Gueye, Aïssatou Mbodji, Aminata Niass, Cyr Espérence Gombet \\ Koulimaya and Jacques Raiga et Alassane Diouf
}

Department of Obstetrics and Gynaecology, National Hospital of Pikine, Senegal

Submission: January 24, 2020; Published: February 10, 2020

*Corresponding author: Moussa Diallo, Department of Obstetrics and Gynaecology, National Hospital of Pikine, Senegal

\begin{abstract}
Objective : To assess the management of advanced ovarian cancer at the Pikine National Hospital Center and to assess his prognosis.

Patients and methods: This is a prospective collection on the surgical management of ovarian cancer between July 2017 and March 2019. This study took place in the Gynecology and Obstetrics department of the National Hospital Center of Pikine. This prospective study brings together the first 37 cases of ovarian cancer managed by optimal surgery. Included were all patients with an ovarian tumor whose diagnosis had been made either after a search for malignant cells in the ascites fluid, or after a histological examination of a biopsy sample by laparoscopy. Were not included in our study, patients who did not benefit from a neither optimal or delayed cytoreductive surgery, or those whose formal diagnosis had not been made.

Result : The average age of the patients was 54 years with extremes of 31 and 79 years. Only two of our patients were nulligestes (0.8\%). The average body mass index was $24 \mathrm{Kg} / \mathrm{m} 2$ with an average weight of $66 \mathrm{~kg}$. Serous papillary adenocarcinoma was the most common histological type (91.1\%). The other histological forms were represented by mucinous cancer (3 cases), the granulosa tumor, the cell-ring tumor with a kitten. The serous papillary carcinomas are all of high grade. Almost all of the patients were in stage III of their disease (82.7\%). Among the 37 patients followed in our department, 29 had undergone optimal debulking surgery. The rest of our patients had received neoadjuvant chemotherapy. That four of them had benefited secondarily from optimal interval surgery. two patients were refractory to chemotherapy and had never been operated on. Two other patients died before any treatment. The quality of surgery was assessed using «completeness cancer resection». The tumor residue was less than $1 \mathrm{~cm}$ in 2 patients, less than $2 \mathrm{~cm}$ in 3 others. In addition, it was zero in 22 patients.
\end{abstract}

Conclusion : This pathology is regularly detected in advanced stages and is most commonly characterized by peritoneal spread of tumor cells, the formation of ascites fluid and the acquisition of chemoresistance. In our situation, neoadjuvant chemotherapy should be systematic in our context beyond stage II of the disease.

Keywords: Ovarian cancer; Serous papillary adenocarcinoma; Neoadjuvant chemotherapy

\section{Introduction}

Ovarian cancer is the third most common cancer in women after breast and uterine cancer. It remains the most lethal. Its severity, directly linked to the frequency of advanced forms and its prognosis, are conditioned by resectability. This pathology is the fourth cause of death from cancer in women according to the National Institute for Public Health Surveillance behind breast, colon and lung cancer with more than 3,000 deaths estimated in $2008[1,2]$. Survival at 5 years, all stages combined, is around $45 \%$ with a worse prognosis for stages III (between 20-40\%) and IV (around 10\%) [3,4].

From 20 years, the treatment of advanced ovarian cancers has been based on the «dogma» of maximum tumor reduction surgery 
combined with chemotherapy. Without changing the dreaded prognosis of this disease, this attitude has made it possible to improve it by better controlling intraperitoneal disease, by overall increasing the survival time by approximately $10 \%$ to 5 years $(20$ to $25 \%$ vs 10 to $15 \%$ ) and allowing certain groups of patients to have prolonged survival [5].

With this in mind, the surgeon's goal is to leave as little tumor residue as possible. This can lead him to make a particularly heavy intervention, comprising one or more or less extensive digestive excesses. Patients must therefore be able to withstand this type of surgery and be prepared accordingly [5]. In subSaharan Africa, the main difficulty remains the problem of postoperative resuscitation and, to a lesser degree, the quality of surgical excision. Furthermore, the contribution of endoscopy in the resectability decision allows a better selection of patients.

In order to evaluate the management of advanced ovarian cancer at the Pikine National Hospital Center, we have proposed a study on this subject. Our goal was:

a) to assess the management of advanced ovarian cancer at the Pikine National Hospital Center;

b) to assess his prognosis.

\section{Patients and methods}

This is a prospective collection on the surgical management of ovarian cancer between July 2017 and March 2019. This study took place in the Gynecology and Obstetrics department of the National Hospital Center of Pikine. This prospective study brings together the first 37 cases of ovarian cancer managed by optimal surgery. Included were all patients with an ovarian tumor whose diagnosis had been made either after a search for malignant cells in the ascites fluid, or after a histological examination of a biopsy sample by laparoscopy. Were not included in our study, patients who did not benefit from a neither optimal or delayed cytoreductive surgery, or those whose formal diagnosis had not been made.

\section{Preoperative Assessment}

The preoperative evaluation included a general and gynecological examination. Pelvic ultrasound, CA 125 marker assay and computed tomography (CT) of the chest, abdomen and pelvis were routinely performed and sometimes pelvic magnetic resonance imaging (MRI). A second reading of the CT scans was necessary to search for signs of major carcinosis, especially in the diaphragmatic domes, the presence of which constitutes a criterion of non-resectability in our practice (Figures 1-3). All patients without medical or anesthetic contraindications to laparoscopy were systematically evaluated by laparoscopy. This strategy allowed us to carry out biopsies and also to make a staging and especially to decide on resectability. Finally, if the optimal surgery was deemed feasible, a conversion to laparotomy was made.
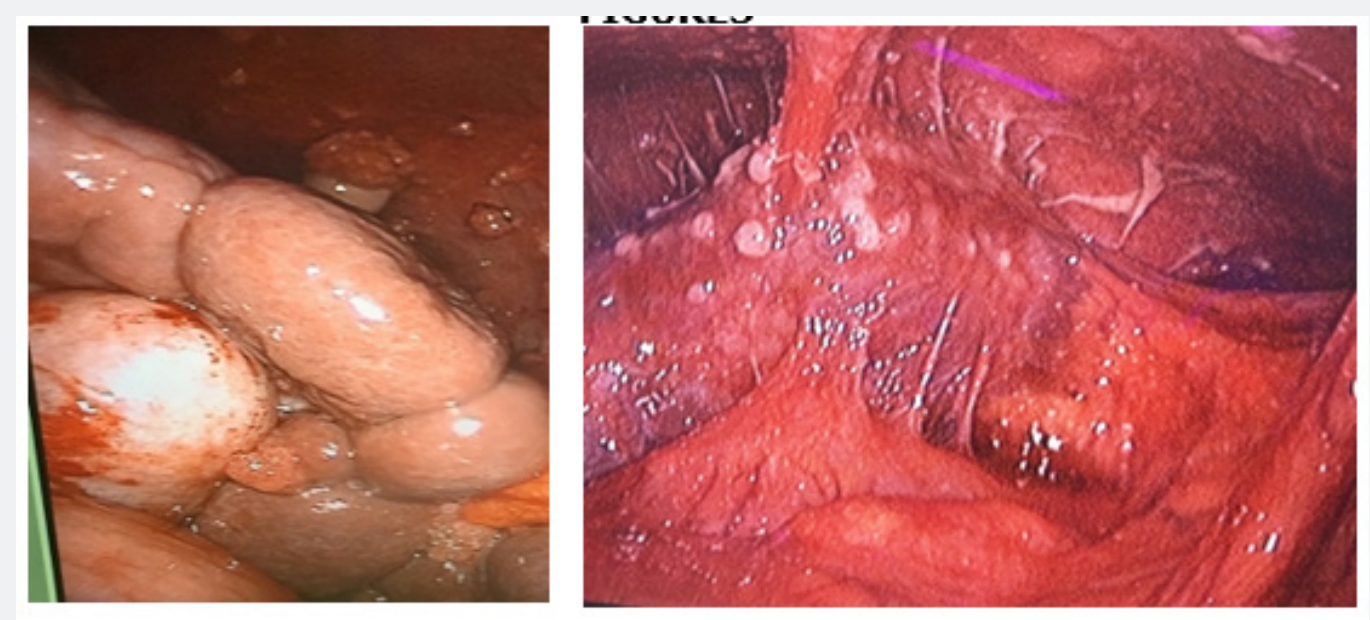

Figure 1: Glisson's capsule retractable carcinosis.

\section{The Operative Stage}

All procedures had been performed by the same team of surgeons. Carbon dioxide was blown in by an approach in the left hypochondrium and then a $10 \mathrm{~mm}$ sub-umbilical trocar was introduced under visual control. A $5 \mathrm{~mm}$ auxiliary trocar was inserted, preferably above the pubic symphysis. The ascites fluid was aspirated and its volume recorded in milliliters. Biopsies were performed to obtain a histological diagnosis. Based on the results 


\section{Journal of Gynecology and Women's Health}

of the laparoscopy, the patients were classified as having a disease that may or may not be resectable. The criteria for neoadjuvant chemotherapy were as follows: need for extensive resections of the digestive tract (massive damage with agglutination) (Figure 1\&4), extensive damage to the mesentery (Figure 2), massive damage to the hepatic pedicle (Figure 5) or diaphragmatic domes or a "frozen" pelvis whose resection would require pelvic exenteration (Figure 3). For each patient, we calculated the Fagotti, and Sugarbaker scores based on laparoscopic results, but these scores were not used to predict resectability. The complexity of the intervention was assessed using the Aletti score.
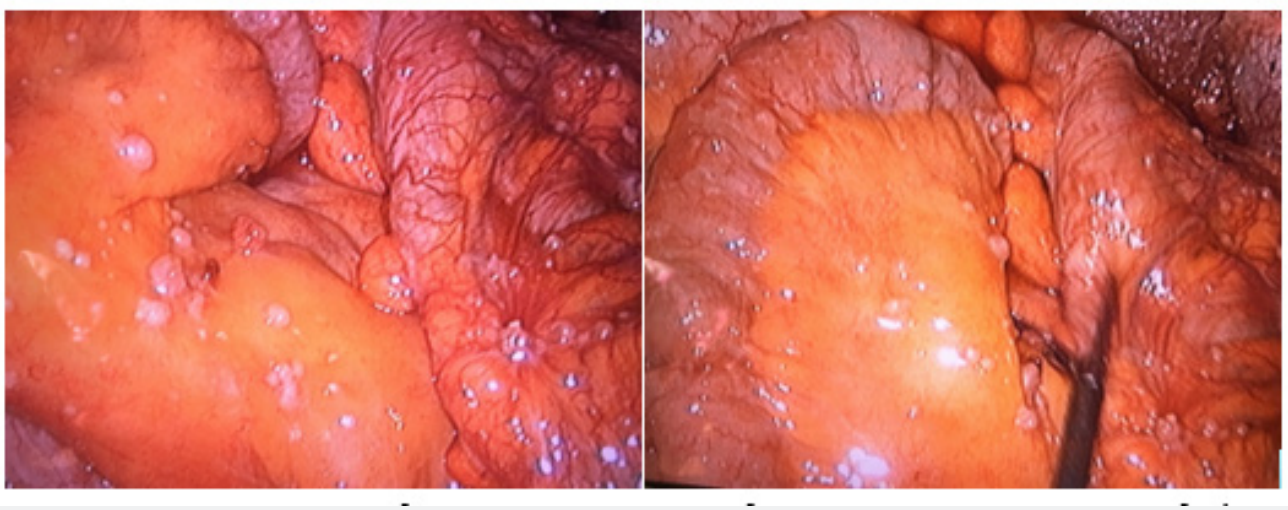

Figure 2: Massive and diffuse carcinosis of the mesentery.

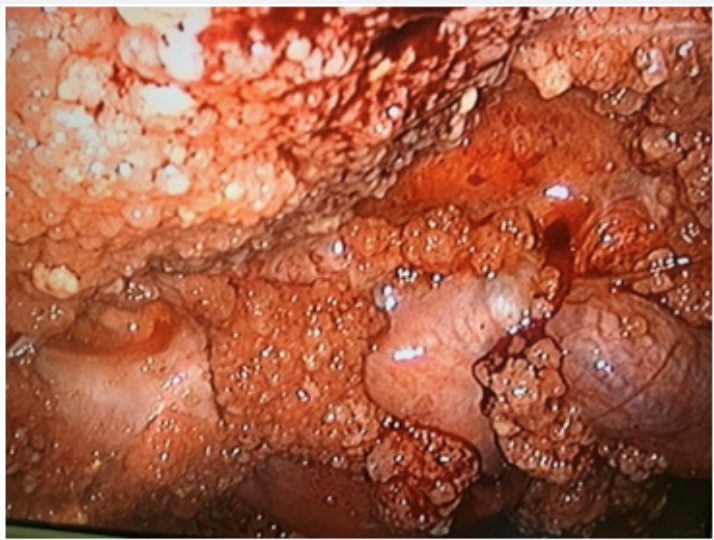

Figure 3: Massive pelvic involvement with peritoneal carcinosis.
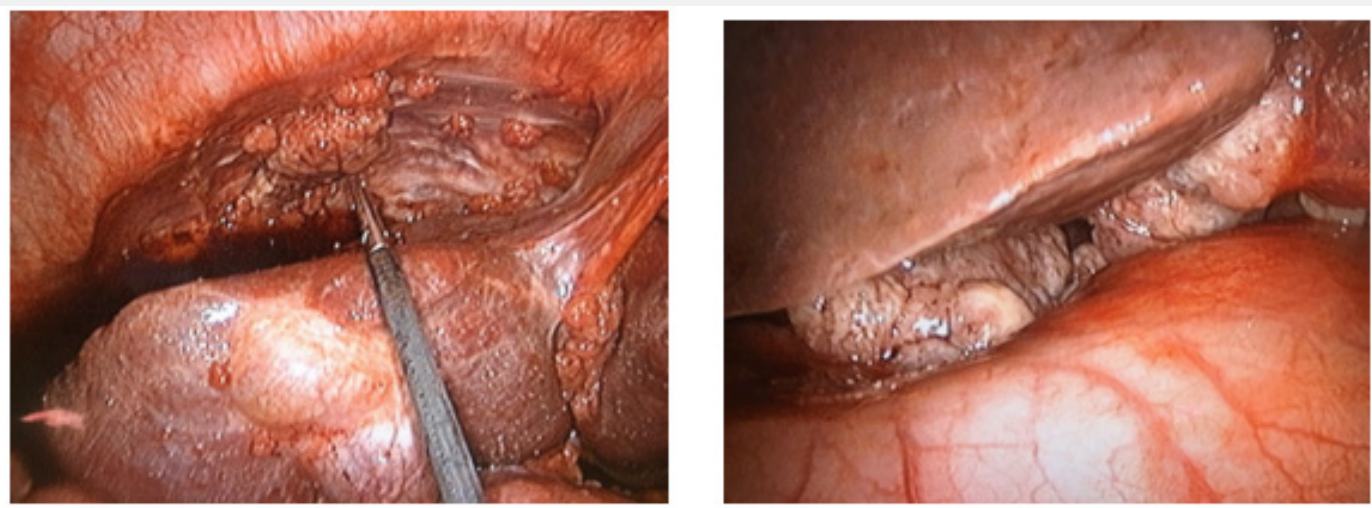

Figure 4: Retractile carcinosis of the diaphragmatic dome. 


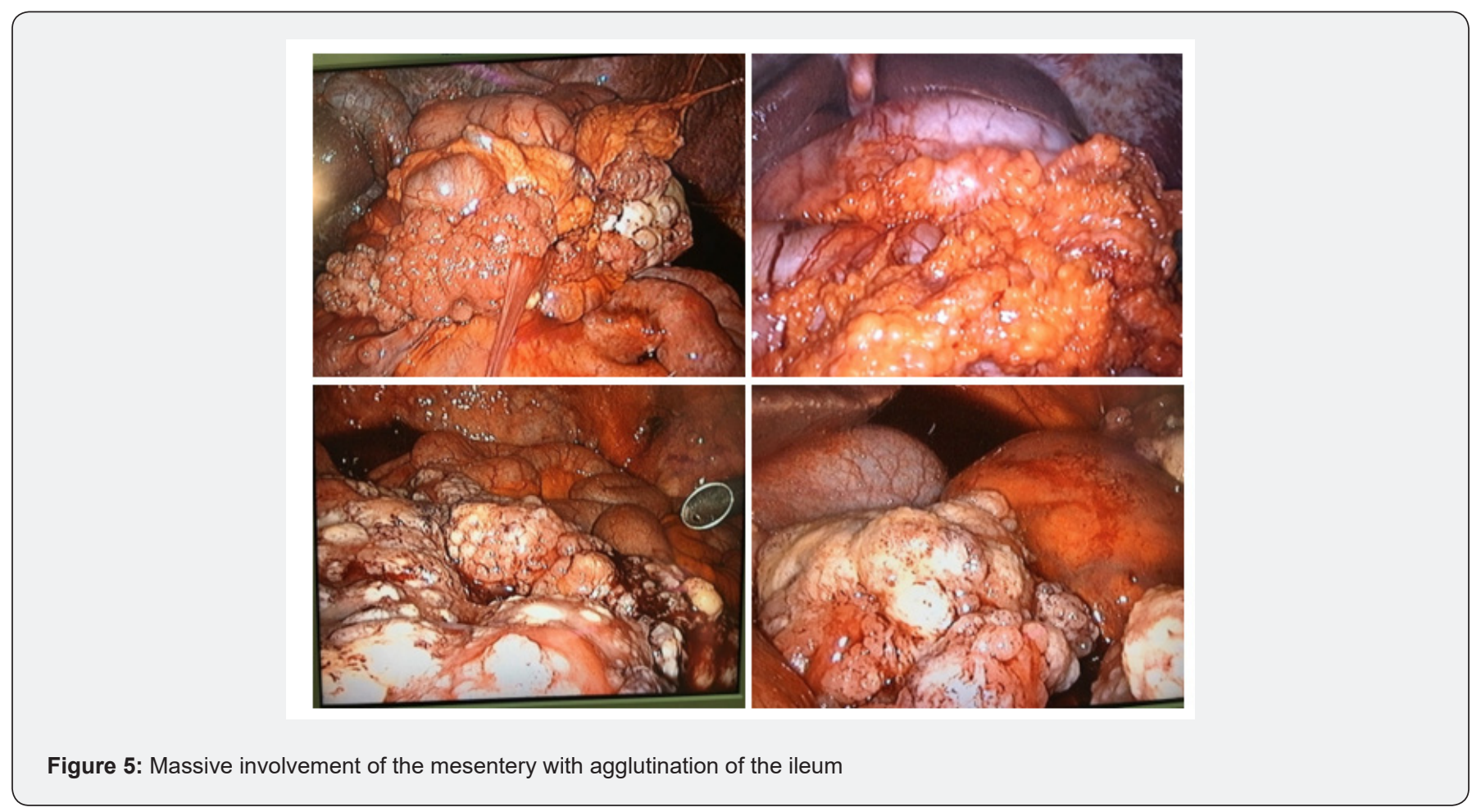

\section{The Post-Operative Stage}

Patients were systematically admitted to intensive care. They had all received a blood transfusion there. Usual care was provided during their hospitalization. Preventive treatment for venous thromboembolic disease was performed with low molecular weight heparin. The operative specimens were then sent to the pathological anatomy laboratory. A detailed report of the intervention was drawn up with a copy given to the patient. It included the results of laparoscopic exploration with evaluation of the peritoneal carcinosis score (Peritoneal carcinosis index and modified Fagotti and Fagotti score), amount of ascites fluid and the different stages of cytoreductive surgery which were evaluated by the Aletti score. The remaining tumor residues were also assessed using a cancer completeness resection score.

\section{Data Entry And Analysis}

Data was captured and analyzed on SPSS 23 software for Macintosh. We are mainly interested in the analysis of socio-demographic data, clinical characteristics, histological characteristics, operative technique and complications of the operative procedure. Data was immediately saved.

Result

\section{Socio-demographic characteristics}

The average age of the patients was 54 years with extremes of 31 and 79 years. Only two of our patients were nulligestes $(0.8 \%)$. The average body mass index was $24 \mathrm{Kg} / \mathrm{m}^{2}$ with an average weight of $66 \mathrm{~kg}$ (Table 1).

Table I : Socio-demographic characteristics.

\begin{tabular}{|c|c|}
\hline Characterictics of Patients & Averages \\
\hline Mean age & 54 years \\
\hline Mean Weight & $66 \mathrm{~kg}$ \\
\hline BMI & $24 \mathrm{~kg} / \mathrm{m}^{2}$ \\
\hline Gestity & 6 \\
\hline Parity & 4 \\
\hline
\end{tabular}

BMI: body mass index

\section{Clinical characteristics}

Only two of our patients had a surgical history; one of an appendectomy and the other of an ovarian cystectomy for an alleged benign lesion. Almost all of the patients presented with an abdominal or pelvic mass (97.1\%). Nineteen patients had ascites. Two patients presented with «Marie Joseph» umbilical nodules at the time of admission. For two patients, the discovery was made from a cystectomy performed for a presumed benign lesion. The average consultation time was 6 months after the onset of the first symptom. The diagnosis was made on examination of the operating room in $71.5 \%$ of the cases, in $5.8 \%$ after a cytology of the ascites fluid and in $11.6 \%$ after a laparoscopic biopsy. This was due to the results of the often unsuccessful search for malignant cells in the peritoneal fluid. As a result, the malignant character was suspected during the laparoscopic examination. The mean of CA 125 level was 491.2 with a maximum level of 1756 IU/ml. It was not correlated with resectability (Table 2). 
Table 2: Clinical, histological and operative characteristics.

\begin{tabular}{|c|c|c|c|c|}
\hline \multicolumn{5}{|c|}{ Patients Characteristics } \\
\hline \multirow[t]{2}{*}{ Histological type } & $\begin{array}{l}\text { Papillary serous adeno- } \\
\text { carcinoma }\end{array}$ & Mucinous adenocarcinoma & $\begin{array}{l}\text { Adenocarcinoma with kitten } \\
\text { ring cells }\end{array}$ & $\begin{array}{c}\text { Endométriod adenocar- } \\
\text { cinoma }\end{array}$ \\
\hline & $31(88,5)$ & $3(0,8)$ & $1(0,2)$ & $1(0,2)$ \\
\hline Histological grade & $\begin{array}{l}\text { Low grade } \\
34(97,1)\end{array}$ & $\begin{array}{l}\text { High grade } \\
1(0,2)\end{array}$ & & \\
\hline \multirow{2}{*}{ FIGO stage } & Ia & II & III & IV \\
\hline & $3(0,6)$ & $2(0,4)$ & $29(82,8)$ & $1(0,2)$ \\
\hline \multirow{2}{*}{ Ascites } & Minimum & Maximum & Average & \\
\hline & 0 & 11000 & 2400 & \\
\hline \multirow{2}{*}{ CA 125 level } & Minimum & Maximum & Average & \\
\hline & 4 & 1756 & 491,2 & \\
\hline \multirow{2}{*}{ PCI score } & 0 & Less than 10 & Greater than 10 & \\
\hline & 3 & 14 & 18 & \\
\hline \multirow{2}{*}{ Fagotti Score } & Score $<2$ & $2<$ Score $<8$ & Score $>8$ & \\
\hline & 21 & 6 & 7 & \\
\hline \multirow{2}{*}{ Aletti Score } & Score $<3$ & $3<$ Score $<7$ & Score $>8$ & \\
\hline & 2 & 24 & 3 & \\
\hline \multirow{2}{*}{ CCR Score } & $1-10 \mathrm{~mm}$ & $11-20 \mathrm{~mm}$ & $>20 \mathrm{~mm}$ & 0 \\
\hline & 2 & 3 & 2 & 22 \\
\hline
\end{tabular}

\section{Histological and operative characteristics}

Serous papillary adenocarcinoma was the most common histological type (91.1\%). The other histological forms were represented by mucinous cancer (3 cases), the granulosa tumor, the cell-ring tumor with a kitten. The serous papillary carcinomas are all of high grade. Among the 37 patients followed in our department, 29 had undergone optimal debulking surgery. The rest of our patients had received neoadjuvant chemotherapy. that four of them had benefited secondarily from optimal interval surgery. two patients were refractory to chemotherapy and had never been operated on. Two other patients died before any treatment.

During this surgery, only two patients had not undergone a laparoscopic evaluation because of the size of the ovarian lesions. The non-resectability decision was retained in 6 patients.

These criteria were represented by:

a. A significant invasion of the mesentery and a significant part of the ileum and jejunum (Figure 2,3,5).

b. Massive carcinosis with confluent lesions on the Glisson capsules and the hepatic pedicle (Figure 1\&4).

c. Massive involvement of the greater omentum with solidification of the stomach and colon and / or ileum (Figure 5). d. Diaphragmatic domes not accessible due to a confluence of carcinomatous lesions (Figure 1).

e. - significant damage to the pelvic organs (bladder and rectum) or a non-dissectable pelvis ("frozen" pelvis).

Almost all of the patients were in stage III of their disease (82.7\%). The average amount of ascites fluid was 2400 cc with extremes of 0 and 11000 cc. A haematological aspect was associated with unresectable cancer in all cases. The laparotomy decision, whenever it was deemed possible, was made successfully (tumor residue absent) in all cases. As a result, laparoscopy was considered more reliable than thoraco-abdomino-pelvic CT. Peritoneal carcinosis was assessed using the Fagotti scores and Sugarbaker's Peritoneal Carcinosis Index (PCI).

The latter, which although conventionally used during laparotomy, because of the ease, was the most used. The optimal resectability threshold is fixed at 10 . It varied from 0 to 35 with an average of 11 . It was less than 10 in 14 patients and more than 10 in 18 other patients. As for the Fagotti score, it varied from 0 to 12. It was less than 2 in 21 patients, between 2 and 8 in 6 patients, the thresholds selected being 2 for total resectability and 8 for incomplete resectability.

The quality of surgery was assessed using «completeness cancer resection». The tumor residue was less than $1 \mathrm{~cm}$ in 
2 patients, less than $2 \mathrm{~cm}$ in 3 others. In addition, it was zero in 22 patients. The complexity of the surgery and the risk of complications were assessed by the Aletti score. In $82.7 \%$ it was between 3 and 7, less than 3 in 2 patients and more than 8 in 3 other patients. For these last three patients, a peritonectomy of the vesico-uterine sac, colonic splints and the anterior abdominal wall were performed in addition to a «douglassectomy» and digestive resections.

The complications encountered during this surgery were:

a. a ureteral section

b. 4 injuries of the inferior vena cava

c. an opening of the bladder.

These various complications were managed during the intervention.

All of the patients had received intraoperative and postoperative blood transfusions.

\section{Post-operative monitoring}

In postoperative follow-up, the main difficulty encountered was long convalescence with an average length of hospital stay of 7 days and extremes of four and 15 days. One case of evisceration was observed in one patient, however. The aforementioned intraoperative complications had no repercussions in the postoperative follow-up. The pathology examination found a pelvic lymph node involvement in two patients. These were the nodes of the common iliac bifurcation and the obturator fossa of an ovarian squamous cell carcinoma (degeneration of an ovarian teratoma). In the latter, the tumor residue was greater than $2 \mathrm{~cm}$ (CCR 3) due to the invasion of the external iliac vessels. Unfortunately, the consequences were fatal to the patient after 4 months of follow-up.

In another patient, an invasion of the latera-aortic nodes was found for a high-grade papillary serous adenocarcinoma. After surgery, all advanced patients had received adjuvant chemotherapy using a platinum salt (carboplatin) and a taxane (paclitaxel) with 3 to 6 courses. Once this chemotherapy was completed, monitoring was continued using the CA 125 assay with a quarterly rate.

\section{Discussion}

\section{Age and BMI}

The average age of patients in our study was 54, range 31 and 79 years of age. Our results were close to those of Elisabeth CHEREAU and colleagues [6] who obtained a: median age of 57 years. Some of the authors who have carried out studies similar to ours have had different results: Nebbali in Algeria [7]: average age at 65 years in Turkey Kimyon Comert: median age of 47 [8]. This confirms to us that ovarian cancer in advanced stages is essentially cancer of the menopausal woman. The number of ovarian carcinomas increases with age and most of these highgrade cancers are seen in postmenopausal women and those at the end of genital activity [9]. The average body mass index was $24 \mathrm{Kg} / \mathrm{m}^{2}$. It is a witness to under nutrition linked to the advanced stage of the disease.

\section{Histological type}

Serous papillary adenocarcinoma was the most frequent histological type (91.1\%) in our study similar to the results of G Kimyon (9), this result confirms those of the French college of pathologies [10]. Serous papillary adenocarcinoma is $50-70 \%$ responsible for advanced high-grade ovarian cancer.

\section{Ascites}

The average amount of ascites fluid was $2400 \mathrm{cc}$ with extremes of 0 and $11000 \mathrm{cc}$ it was more related to the ascito-tumor syndrome of advanced ovarian cancers. Its presence in large quantities was not correlated with the possibility of surgery [11-13].

\section{The different operating scores}

The operative scores used in our study were: the Fagotti score, the Alleti score, the Sugarbaker Peritoneal Carcinosis Index (PCI) and the quality of the surgery was assessed using «completeness cancer resection» $[14,15]$.

\section{Operative complications}

The complications encountered during our study were: a ureteral section, 4 injuries of the inferior vena cava, a bladder opening. All of the patients had received an intraoperative and postoperative blood transfusion. Chéreau $[6,16]$ operational complications $54 \%$ (33 patients), $41 \%$ of patients were transfused with $955 \mathrm{ml}$ of blood loss, $6 \%$ of intestinal fistulas and $52 \%$ of patients presented with fever. These results are justified with the results of the operating scores obtained in our study in Table 2.

\section{Prognosis}

The prognosis of patients in the management of advanced ovarian cancer is strongly linked to its local extension, regional damage, FIGO and TNM classifications and the extent of peritoneal carcinosis. Tumors without peritoneal carcinosis can be considered to be lower risk of recurrence while taking into account tumor volume and abdominopelvic extension. In addition, the size and capsular rupture of the lymph nodes are important prognostic factors significantly associated with both overall survival and poorer recurrence-free survival. In addition, survival is strongly correlated with the quality of surgery. Thus, it is imperative to 
obtain an optimal quality of resection during surgery (absence of macroscopic residue) according to the recommendations of SaintPaul de Vence of 2019 [13,16].

In our study, in addition to the operational complications found, we encountered postoperative complications:

a. 1 case of evisceration

b. 2 cases of pelvic lymph node invasion

Regarding mortality in our study, we had one death. It was one of two patients whose pathology report had identified lymph node involvement. These were the nodes of the common iliac bifurcation and the obturator fossa for an ovarian squamous cell carcinoma (degeneration of an ovarian teratoma). In the latter, the tumor residue was greater than $2 \mathrm{~cm}$ (CCR 3 ) due to the invasion of the external iliac vessels. Unfortunately, the consequences were fatal to the patient after 4 months of follow-up.

\section{Conclusion}

This pathology is regularly detected in advanced stages and is most commonly characterized by peritoneal spread of tumor cells, the formation of ascites fluid and the acquisition of chemoresistance. Its lethality in relation to the complexity of the treatment which requires criteria of operability, resectability, the extension of peritoneal carcinosis requires treatment as soon as possible by a multidisciplinary medical and surgical team. Through these first cases managed, we can say that it is possible to manage these cancers, even at an advanced stage in an optimal way and thus improve the survival of the patients. For this, neoadjuvant chemotherapy should be systematic in our context beyond stage II of the disease.

\section{References}

1. Banks E, Valerie B, Gillian R (1997) The epidemiology of epithelial ovarian cancer: a review. Int J Gynecol Cancer 7(6): 425-438.

2. Beral V, Doll R, Hermon C, Peto R, Reeves G, et al. (2008) Ovarian cancer and oral contraceptives: collaborative reanalysis of data from 45 epidemiological studies including 23,257 women with ovarian cancer and 87,303 controls. Lancet 371(9609): 303-314.
3. Chen V, Ruiz B, Kileen J, Coté TR, Wu XC, et al. (2003) Pathology and classification of ovarian tumors. Cancer 97(10 Suppl): 2631-2642.

4. (2009) Collège Français des pathologistes (Copath). Disponible sur consulté le 16/06/2019.

5. (2018) Conduites à tenir initiales devant des patientes atteintes d'un cancer épithélial de l'ovaire / Synthèse, novembre 2018. Disponible sur : e-cancer.fr.

6. Dauplat J, Le Bouëdec G, Pomel C, Scherer C (2000) Cytoreductive surgery for advanced stages of ovarian cancer. Sem Surg Oncol 19(1): 42-48.

7. Chéreau E, Ballester M, Frédéric S, Cortez A, Daraï E, et al. (2010) Comparison of peritoneal carcinomatosis scoring methods in predicting respectability and prognosis in advanced ovarian cancer. Am J Obstet Gynecol 202(2): 178.e1-178.e10

8. (2014) Fédération Internationale de Gynécologie et d'ObstétriqueClassification des tumeurs de l'ovaire [Internet].

9. Kimyon Comert G, Turkmen O, Mesci CG, Karalok A, Sever 0, et al. (2018) Maximal cytoreduction is related to improved disease-free survival in low-grade ovarian serous carcinoma. Tumori 105(3): 259264.

10. http://www.ecancer.fr/

11. Musto A, Grassetto G, Marzola MC, Rampin L, Chondrogiannis, et al. (2014) Management of epithelial ovarian cancer from diagnosis to restaging: an overview of the role of imaging techniques with particular regard to the contribution of 18F-FDG PET/CT. Nucl Med Commun 35(6): 588-597.

12. Prat J, FIGO Committee on Gynecologie Oncology (2014) Staging classification for cancer of the ovary, fallopian tube, and peritoneum. Int J Gynaecol Obstet 124(1): 1-5.

13. Joly F, Querleu D, Namer M, Pujade-Lauraine E (2017) Mise à jour 2016 des recommandations pour la pratique clinique de Nice/SaintPaul-de-Vence dans le cancer de l'ovaire et du col de l'utérus à un stade avancé. Bull Cancer 104 (Suppl 1): S1-S5.

14. Webb PM, Jordan SJ (2017) Epidemiology of epithelial ovarian cancer. Best Pract Res Clin Obstet Gynaecol 41: 3-14.

15. Van der Burg ME, van Lent M, Buyse M, Kobierska A, Colombo N, et al. (1995) The effect of debulking surgery after induction chemotherapy on the prognosis in advanced epithelial ovarian cancer. Gynecological Cancer Cooperative Group of the European Organization for Research and Treatment of Cancer. N Engl JMed 332(10): 629-34.

16. Wimberger P, Wehling M, Lehmann N, Kimmig R, Schmalfeldt B, et al. (2010) Influence of residual tumor on outcome in ovarian cancer patients with FIGO stage IV disease: an exploratory analysis of the AGO- OVAR (Arbeitsgemeinschaft Gynaekologische Onkologie OvarianCancer Study Group). Ann Surg Oncol 17(6): 1642-1648. 

(CC) This work is licensed under Creative DOI: 10.19080/JGWH.2020.18.555986

\section{Your next submission with Juniper Publishers will reach you the below assets}

- Quality Editorial service

- Swift Peer Review

- Reprints availability

- E-prints Service

- Manuscript Podcast for convenient understanding

- Global attainment for your research

- Manuscript accessibility in different formats ( Pdf, E-pub, Full Tsext, Audio)

- Unceasing customer service

Track the below URL for one-step submission https://juniperpublishers.com/online-submission.php 